\title{
A Model of Flame Propagation in Rich Mixtures of Coal Dust in Air
}

\author{
SCOTT E. SLEZAK \\ Department of Mechanical Engineering and Applied Mechanics, University of Michigan-Ann Arbor, MI \\ and \\ RICHARD O. BUCKIUS and HERMAN KRIER \\ Department of Mechanical and Industrial Engineering, University of Illinois at Urbana-Champaign, IL
}

\begin{abstract}
A two-phase combustion model describing fundamental coal dust flame propagation phenomena is developed to treat general fuel rich mixtures. The model includes heterogeneous combustion, pyrolysis of the coal, and homogeneous combustion of volatile matter and the optically thick limit for radiative heat transfer. Calculations for coal (fuel) rich mixtures in air were done for equivalence ratios of 3-8. Predicted burning velocities for $50 \mu \mathrm{m}$ particles of coal with $36 \%$ volatile matter indicated a broad maximum of $37 \mathrm{~cm} / \mathrm{s}$ at an equivalence ratio of $4\left(0.367 \mathrm{~kg} / \mathrm{m}^{3}\right)$. The minimum computed velocity was $9 \mathrm{~cm} / \mathrm{s}$ at $\phi=8\left(0.733 \mathrm{~kg} / \mathrm{m}^{3}\right)$. The burning velocity was found to increase as the particle size decreased. The chemical kinetics model was highly simplified, but based on experimental information. The predicted flame temperatures and structures compare well with recent experimental data published by the authors. The structure of the flames was found to be strongly influenced by radiative heat transfer. Flame thicknesses were predicted to exceed $10 \mathrm{~cm}$ for most conditions studied.
\end{abstract}

\section{INTRODUCTION}

The combustion of coal dust in air has been a topic of continuing flammability research for over a half a century. That research sought to determine fundamental properties of flame speed, energy release, and propagation limit concentrations for a wide variety of pulverized coals. Two extensive review papers, by Smoot and Horton [1] and Krazinski et al. [2], have attempted to assess several hundred published studies and catalog the experimental results. A recent paper by Slezak et al. [3] presents additional assessment of coal dust flammability studies. It is clear that the heterogeneous nature of pulverized coal/air combustion is compli-

Copyright $@ 1985$ by The Combustion Institute Published by Elsevier Science Publishing Co., Inc. 52 Vanderbilt Avenue, New York, NY 10017 cated because of the wide variety of coals, the range of dust particle sizes, the difficulty in supporting uniform mixtures of coal in air, and the global effects of buoyancy and heat loss which occur due to the experimental apparatus/ techniques.

Clearly, steady-state combustible coal and air mixtures are fuel rich, as discussed in Refs. [13]. An analysis to predict the (adiabatic, laminar flow) propagation of coal dust flames must also model rich mixtures.

All one-dimensional, laminar flame propagation models for coal dust and air mixtures have contained simplifications which were necessary to describe the dust combustion processes. The models of Essenhigh and Csaba [4] and Bhaduri

$0010-2180 / 85 / \$ 03.30$ 
and Bandyopadhyay [5] both neglected temperature differences between the coal and the gas. The thermal model of Essenhigh and Csaba also did not include devolatilization or chemical reactions. Bhaduri and Bandyopadhyay considered a simple heterogeneous reaction, but devolatilization and homogeneous reactions were not included in their model. A more realistic radiation model and temperature differences between the gas and particles were allowed in the model of Ozerova and Stepanov [6], but their work did not include volatiles combustion. Smoot et al. [1] formulated a more comprehensive model for both heterogeneous combustion of char and homogeneous combustion of volatiles. Krazinski et al. [2] included realistic radiation modeling with their basic description of both char and volatiles combustion. The model presented in Ref. [2] was strictly limited to stoichiometric mixtures. Because of the numerical integration analysis (shooting technique) used in Ref. [2], no rich coal mixtures could be modeled.

A model is therefore presented herein which is based, in part, on the analysis of Ref. [2], but which is formulated to treat the generalized problem of both lean, stoichiometric and rich coal dust-air mixtures. Here the conservation equations are expressed in their proper unsteady-state form, requiring a solution by the method of lines to provide for the relaxed steady-state results. For nonstoichiometric mixtures, the problem is complicated because the conditions at the hot (burned-out) end are not all known a priori. For example, the amount of gaseous volatiles, excess coal, and gaseous $\mathrm{O}_{2}$ or $\mathrm{CO}_{2}$ remaining are a function of the entire thermal reaction history in the flame zone, allowing one to apply only the standard zerogradient boundary conditions at the hot boundary $(x \rightarrow+\infty)$.

\section{THE MODEL}

The model includes heterogeneous combustion of char, homogeneous combustion of volatiles and radiative heat transfer, and also allows for temperature differences between the coal parti- cles and gas. More important, while any fuel/air ratio can be used, only fuel (coal) rich mixtures are specifically considered. The model conservation equations are based on the concepts of continuum mechanics, with fundamental assumptions underlying the continuum mechanics of multiphase flows as found in Soo [7].

In our somewhat simplified model the chemical formula for coal is assumed to be $\mathrm{CH}_{0.8}$. It is assumed that the products of combustion include only one volatile species, $\mathrm{C}_{3} \mathrm{H}_{8}$, and $\mathrm{CO}_{2}$ and $\mathrm{H}_{2} \mathrm{O}$ as products of both the homogeneous (volatile/air) combustion and hetergeneous reaction. Nitrogen is assumed inert and for the fuel rich cases, no excess $\mathrm{O}_{2}$ exists, but it is possible to predict unburned volatiles $\left(\mathrm{C}_{3} \mathrm{H}_{8}\right)$.

Thus, the overall reaction for the "coal" modeled here may be written as

$$
\begin{aligned}
& \phi\left(0.7 \mathrm{C}+0.1 \mathrm{C}_{3} \mathrm{H}_{8}\right)+1.2\left(\mathrm{O}_{2}+3.76 \mathrm{~N}_{2}\right) \rightarrow \\
& a \mathrm{CO}_{2}+b \mathrm{H}_{2} \mathrm{O}+d \mathrm{C}+e \mathrm{C}_{3} \mathrm{H}_{8}+f \mathrm{O}_{2}+4.512 \mathrm{~N}_{2} .
\end{aligned}
$$

For a very rich case, $\phi=8$, the steady solution of the conservation equations yields $a=$ $0.8898, b=0.6205, d=5.176, e=0.6448$, and $f=0$.

The heterogeneous reaction included in the model for the results presented in this work is given by the simple equation $\mathrm{C}(s)+\mathrm{O}_{2} \rightarrow \mathrm{CO}_{2}$. The failure to include the formation of $\mathrm{CO}$ through either this reaction or the homogeneous reaction given below is a deficiency of this model.

The heat of formation of $\mathrm{CO}$ is only about one-third that of $\mathrm{CO}_{2}$, and, therefore, reactions which include the formation of carbon monoxide will release less energy and the temperature of combustion will be correspondingly lower. (Some justification for the exclusion of $\mathrm{CO}$ from the work presented here is that experimental evidence indicates [8] that at higher temperatures of combustion the heterogeneous combustion of carbon results in the formation of greater amounts of $\mathrm{CO}_{2}$ than at lower temperatures.) At the higher temperatures the carbon monoxide formed at the carbon surface reacts further to carbon dioxide before it is able to diffuse far away from the source carbon surface. Since this 
modeling effort is for an adiabatic flame, the temperatures are expected to be greater than those obtained in comparable experiments. The adiabaticity would thus cause more complete combustion to result, and the combustion reactions included in the work presented here may then retain some validity. Additionally, a major emphasis in this work was to investigate the influence of radiative heat transfer in fuel rich dust combustion. Nonetheless, the formation of $\mathrm{CO}$ and $\mathrm{H}_{2}$ can become significant as the mixtures become more fuel rich. Including these species is an effort planned for future work.

As mentioned, the coal considered in this model was assumed to have the overall composition of $\mathrm{CH}_{b}$. A value of $b$ near unity is indicative of a bituminous coal with high volatiles yield, while a small value of $b$ is indicative of an anthracite with a very high fixed carbon content. Trace amounts of nitrogen, oxygen, and sulfur which exist in most real coals were assumed to be negligible. Ash was also not included in the description of the coal. The role of ash in fuel rich combustion, such as that being modeled here, is relatively minor since large amounts of solid carbon remain unburned. The role of oxygen which is originally present in real coals may be overshadowed by the oxygen present in the air. The coal was assumed to pyrolyze according to the reaction $\mathrm{CH}_{b} \rightarrow d \mathrm{C}+e \mathrm{C}_{n} \mathrm{H}_{m}$. The values of $d$ and $e$ are determined by the value of $b$ and the assumed composition for the volatiles. Conservation of hydrogen determines the value of $e$, as $e=b / m$. This in turn determines $d$, through conservation of carbon, as $d=1-e n$.

The devolatilization model retained by this work is a single step Arrhenius-type reaction. The inclusion of more advanced models is possible, but the advanced devolatilization models have been included only in studies which exclusively studied particular aspects of the coal dust combustion process. No comprehensive dust combustion model to date has included a devolatilization scheme more advanced than that used in this work.

A gas-phase volatiles combustion reaction used here was assumed to be adequately de- scribed by the single step relation [9] $\mathrm{C}_{n} \mathrm{H}_{m}+$ $(n+m / 4) \mathrm{O}_{2} \rightarrow n \mathrm{CO}_{2}+(m / 2) \mathrm{H}_{2}$, where $n=$ 3 and $m=8$ for these calculations, and $b$ was 0.8 for the results presented.

Numerous additional assumptions were made in the development of the model and are given in Ref. [2].

The coal dust combustion model is restricted to one-dimensional laminar two-phase flame propagation. The equations are presented in their transient non-dimensional form since unsteady equations are required by the method of the lines solution technique. Detailed derivations are found in Ref. [10], where the species source/sink terms are also given. One must solve the following set:

Continuity Equation:

$\frac{\partial \rho_{\mathrm{m}} *}{\partial t^{*}}+\frac{\partial\left(\rho_{\mathrm{m}}^{*} u^{*}\right)}{\partial x^{*}}=0$

Mass Balance Equation for Fixed Carbon:

$\rho_{\mathrm{m}} * \frac{\partial Z_{\mathrm{fc}}}{\partial t^{*}}+\rho_{\mathrm{m}} * u^{*} \frac{\partial Z_{\mathrm{fc}}}{\partial x^{*}}=\frac{L_{\mathrm{c}}}{\rho_{\mathrm{m}_{0}} u_{0}} \Gamma_{\mathrm{c}} ;$

Mass Balance Equation for Solid Volatiles:

$\rho_{\mathrm{m}} * \frac{\partial Z_{\mathrm{v}}}{\partial t^{*}}+\rho_{\mathrm{m}} * u^{*} \frac{\partial Z_{\mathrm{v}}}{\partial x^{*}}=\frac{L_{\mathrm{c}}}{\rho_{\mathrm{m}} u_{0}} \Gamma_{\mathrm{v}} ;$

Mass Balance Equation for $\mathrm{CO}_{2}$ :

$$
\begin{aligned}
\rho_{\mathrm{m}} * \frac{\partial}{\partial t^{*}}\left[Y_{\mathrm{CO}_{2}}\right]+\rho_{\mathrm{m}} * u^{*} \frac{\partial}{\partial x^{*}}\left[Y_{\mathrm{CO}_{2}}\right] \\
=\frac{D_{\mathrm{g} 0}}{u_{0} L_{\mathrm{c}}\left(T_{0}\right)^{1.75}} \frac{\partial}{\partial x^{*}}\left[\rho_{\mathrm{m}}{ }^{*}\left(T_{\mathrm{g}}\right)^{1.75}\right. \\
\left.\quad \times\left\{\frac{\partial Y_{\mathrm{CO}_{2}}}{\partial x}+\frac{Y_{\mathrm{CO}_{2}}}{(1-Z)} \frac{\partial Z}{\partial x^{*}}\right\}\right] \\
\quad+\frac{L_{\mathrm{c}}}{\rho_{\mathrm{m}} u_{0}} \Gamma_{\mathrm{CO}_{2}}
\end{aligned}
$$


Mass Balance Equation for $\mathrm{H}_{2} \mathrm{O}$ :

$$
\begin{aligned}
\rho_{\mathrm{m}} * \frac{\partial}{\partial t^{*}}\left[Y_{\mathrm{H}_{2} \mathrm{O}}\right]+\rho_{\mathrm{m}} * u^{*} \frac{\partial}{\partial x^{*}}\left[Y_{\mathrm{H}_{2} \mathrm{O}}\right] \\
=\frac{D_{\mathrm{g} 0}}{u_{0} L_{\mathrm{c}}\left(T_{0}\right)^{1.75}} \frac{\partial}{\partial x^{*}}\left[\rho_{\mathrm{m}} *\left(T_{\mathrm{g}}\right)^{1.75}\right. \\
\left.\quad \times\left\{\frac{\partial Y_{\mathrm{H}_{2} \mathrm{O}}}{\partial x^{*}}+\frac{Y_{\mathrm{H}_{2} \mathrm{O}}}{(1-Z)} \frac{\partial Z}{\partial x^{*}}\right\}\right] \\
\quad+\frac{L_{\mathrm{c}}}{\rho_{\mathrm{m}_{0}} u_{0}} \Gamma_{\mathrm{H}_{2} \mathrm{O}}
\end{aligned}
$$

Mass Balance Equation for Gaseous Volatiles:

$$
\begin{aligned}
\rho_{\mathrm{m}} * \frac{\partial}{\partial t^{*}}\left[Y_{\mathrm{v}}\right]+\rho_{\mathrm{m}}{ }^{*} u^{*} \frac{\partial}{\partial x^{*}}\left[Y_{\mathrm{v}}\right] \\
=\frac{D_{\mathrm{g} 0}}{u_{0} L_{\mathrm{c}}\left(T_{0}\right)^{1.75}} \frac{\partial}{\partial x^{*}}\left[\rho_{\mathrm{m}} *\left(T_{\mathrm{g}}{ }^{*}\right)^{1.75}\right. \\
\left.\quad \times\left\{\frac{\partial Y_{\mathrm{v}}}{\partial x^{*}}+\frac{Y_{\mathrm{v}}}{(1-Z)} \frac{\partial Z}{\partial x^{*}}\right\}\right] \\
+\frac{L_{\mathrm{c}}}{\rho_{\mathrm{m}_{0}} u_{0}} \Gamma_{\mathrm{hc}}-\frac{L_{\mathrm{c}}}{\rho_{\mathrm{m}_{0}} u_{0}} \Gamma_{\mathrm{v}}
\end{aligned}
$$

Particle Energy Equation:

$$
\begin{aligned}
\frac{\partial}{\partial t^{*}}\left[\mathrm{ZC}_{\mathrm{p}}^{*}\left(T_{\mathrm{c}}^{*}-T_{0}^{*}\right)\right] \\
+\rho_{\mathrm{m}} u^{*} \frac{\partial}{\partial x^{*}}\left[Z C_{\mathrm{p}}^{*}\left(T_{\mathrm{c}}^{*}-T_{0}^{*}\right)\right] \\
=\frac{F_{\mathrm{gc}} L_{\mathrm{c}}}{\rho_{\mathrm{m}_{0}} u_{0} C_{\mathrm{p}, \mathrm{g}}}\left(T_{\mathrm{g}}^{*}-T_{0}^{*}\right) \\
\quad+\frac{16 \sigma T_{\mathrm{r}}^{3}}{3 \rho_{\mathrm{m}_{0}} u_{0} C_{\mathrm{p}, \mathrm{g}}} \frac{\partial}{\partial x^{*}}\left(\frac{T_{\mathrm{c}}^{* 3}}{\kappa^{*}} \frac{\partial T_{\mathrm{c}}^{*}}{\partial x^{*}}\right) \\
\quad+\frac{L_{\mathrm{c}}}{\rho_{\mathrm{m}_{0}} u_{0} C_{\mathrm{p}, \mathrm{g}} T_{r}}\left(h_{\mathrm{cg}}{ }^{0} \Gamma_{\mathrm{v}}+h_{\mathrm{coal}}{ }^{0} \Gamma_{\mathrm{c}}\right)
\end{aligned}
$$

Mixture Energy Equation:

$$
\begin{array}{rl}
\rho_{\mathrm{m}} * & * \frac{\partial}{\partial x^{*}}\left[Z C_{\mathrm{p}} *\left(T_{\mathrm{c}}^{*}-T_{0} *\right)\right. \\
& \left.+(1-Z)\left(T_{\mathrm{g}}{ }^{*}+T_{0} *\right)\right] \\
& +\rho_{\mathrm{m}}{ }^{*} u^{*} \frac{\partial}{\partial x^{*}}\left[Z C_{\mathrm{p}}^{*}\left(T_{\mathrm{c}}^{*}-T_{0}^{*}\right)\right. \\
& \left.+(1-Z)\left(T_{\mathrm{g}}^{*}-T_{0}^{*}\right)\right]
\end{array}
$$

$$
\begin{gathered}
=\frac{\lambda_{\mathrm{g}, 0}}{L_{\mathrm{c}} \rho_{\mathrm{m} 0} u_{0} C_{\mathrm{p}, \mathrm{g}}\left(T_{0}^{*}\right)^{0.75}} \frac{\partial}{\partial x^{*}}\left[\left(T_{\mathrm{g}}{ }^{* 0.75} \frac{d T_{\mathrm{g}}{ }^{*}}{\partial x^{*}}\right]\right. \\
\quad+\frac{16 \sigma T_{\mathrm{r}}^{3}}{3 \rho_{\mathrm{m} 0} u_{0} C_{\mathrm{p}, \mathrm{g}}} \frac{\partial}{\partial x^{*}}\left(\frac{T_{\mathrm{c}}^{* 3}}{\kappa^{*}} \frac{\partial T_{\mathrm{c}}^{*}}{\partial x^{*}}\right) \\
\quad+\frac{L_{\mathrm{c}}}{\rho_{\mathrm{m} 0} u_{0} C_{\mathrm{p}, \mathrm{g}} T_{r}}\left(\mathrm{~h}_{\mathrm{het}}^{0} \Gamma_{\mathrm{c}}+h_{\mathrm{hc}}^{0} \Gamma_{\mathrm{hc}}+h_{\mathrm{cg}}{ }^{0} \Gamma_{\mathrm{v}}\right) ;
\end{gathered}
$$

Gas State Equation:

$\rho_{\mathrm{g}} * T_{\mathrm{g}} *=\frac{P_{\mathrm{g}} \mathrm{MW}_{\mathrm{g}}}{\bar{R} \rho_{\mathrm{m}_{0}} T_{\mathrm{r}}}$

Particle Density Equation:

$\rho_{\mathrm{c}}^{*}=\left(\frac{Z_{\mathrm{v}}}{Z_{0}}\right) \rho_{\mathrm{c}, 0}{ }^{*}+\left(1-v_{0}\right) \rho_{\mathrm{c}, 0} * ;$

Conservation of Mass for the Mixture:

$Y_{\mathrm{N}_{2}}+Y_{\mathrm{O}_{2}}+Y_{\mathrm{v}}+Y_{\mathrm{CO}_{2}}+Y_{\mathrm{H}_{2} \mathrm{O}}+Z_{\mathrm{fc}}+Z_{\mathrm{v}}=1$;

Conservation of Mass for the Coal:

$Z=Z_{\mathrm{fc}}+Z_{\mathrm{v}}$

Gaseous Molecular Weight Equation:

$$
\begin{aligned}
(\mathrm{MW})_{\mathrm{g}} & =(1-Z)\left[\frac{Y_{\mathrm{N}_{2}}}{(\mathrm{MW})_{\mathrm{N}_{2}}}+\frac{Y_{\mathrm{O}_{2}}}{(\mathrm{MW})_{\mathrm{CO}_{2}}}\right. \\
& \left.+\frac{Y_{\mathrm{CO}_{2}}}{(\mathrm{MW})_{\mathrm{CO}_{2}}}+\frac{Y_{\mathrm{H}_{2} \mathrm{O}}}{(\mathrm{MW})_{\mathrm{H}_{2} \mathrm{O}}}+\frac{Y_{\mathrm{v}}}{(\mathrm{MW})_{\mathrm{v}}}\right]^{-1} .
\end{aligned}
$$

All variables are defined in the Nomenclature; the source terms, $\Gamma_{\mathrm{v}}(\mathrm{kg}$ of volatiles per unit time and per unit volume), $\Gamma_{c}$ ( $\mathrm{kg}$ of fixed carbon $\left./ \mathrm{s} \mathrm{m}^{3}\right)$, and $\Gamma_{\mathrm{hc}}(\mathrm{kg}$ of hydrocarbons $/ \mathrm{s}$ $\mathrm{m}^{3}$ ), are those used in Ref. [2]. The exponent 1.75 on $T_{\mathrm{g}}{ }^{*}$ in Eqs. (4)-(6) and 0.75 in Eq. (8) originate in the empirical temperature dependent correlations for the diffusivity and conductivity of the gas, respectively, as presented in Ref. [2]. Numerical values for kinetic and physical constants are listed in Table 1 , and the $\Gamma$ expressions are given in Table 2.

Note that in the particle energy equation, the optically thick approximation is assumed as an appropriate limit to model radiative transport. 
TABLE 1

Physical Constants and Parameters

\begin{tabular}{|c|c|}
\hline Parameter & Value \\
\hline$A_{\mathrm{d}}:$ preexponential factor for devolatilization & $5 \times 10^{5} \mathrm{~s}^{-1}$ \\
\hline$A_{\text {hc }}:$ preexponential factor for hydrocarbon reaction & $5.52 \times 10^{8}$ \\
\hline$C_{p, c}:$ specific heat of coal & $1790.0 \mathrm{~J} / \mathrm{kg} \mathrm{K}$ \\
\hline$C_{\mathrm{p}, \mathrm{g}}:$ specific heat of gas & $1140.0 \mathrm{~J} / \mathrm{kg} \mathrm{K}$ \\
\hline$D_{g, 0}:$ gaseous diffusion coefficient & $1.750 \times 10^{-5} \mathrm{~m}^{2} / \mathrm{s}$ \\
\hline$E_{1}:$ activation energy of heterogeneous reaction of coal & $5.439 \times 10^{7} \mathrm{~J} / \mathrm{kmol}$ \\
\hline$E_{\mathrm{d}}:$ activation energy of devolatilization & $7.4 \times 10^{7} \mathrm{~J} / \mathrm{kmol}$ \\
\hline$E_{\mathrm{hc}}:$ activation energy of hydrocarbon reaction & $1.031 \times 10^{8} \mathrm{~J} / \mathrm{kmol}$ \\
\hline$h_{\mathrm{cg}}{ }^{0}:$ heat of sublimation of the volatiles & $1.724 \times 10^{6} \mathrm{~J} / \mathrm{kg}$ \\
\hline$h_{\mathrm{hc}}{ }^{0}$ : heat of reaction of the volatiles & $-4.6353 \times 10^{7} \mathrm{~J} / \mathrm{kg}$ \\
\hline$h_{\text {het }}{ }^{0}$ : heat of reaction for heterogeneous reaction of the coal & $-1.70 \times 10^{7} \mathrm{~J} / \mathrm{kg}$ \\
\hline $\mathrm{MW}_{\mathrm{v}}$ : molecular weight of volatiles $\left(\mathrm{C}_{3} \mathrm{H}_{8}\right)$ & $44.0962 \mathrm{~kg} / \mathrm{kmol}$ \\
\hline Nu: Nusselt number & 2 \\
\hline$P_{\mathrm{g}}:$ pressure & $1.01325 \times 10^{5} \mathrm{~Pa}$ \\
\hline$Q_{\mathrm{abs}}:$ absorption efficiency & 0.84 \\
\hline$Q_{\text {sca }}:$ scattering efficiency & 0.16 \\
\hline$\widetilde{R}$ : universal gas constant & $8314.34 \mathrm{~J} / \mathrm{kmol} \mathrm{K}$ \\
\hline$T_{0}$ : initial temperature & $298 \mathrm{~K}$ \\
\hline$\lambda_{\mathrm{g}, 0}:$ thermal conductivity of gas $298 \mathrm{~K}$ & $0.0252 \mathrm{~W} / \mathrm{m} \mathrm{K}$ \\
\hline$\pi$ & 3.1415926535898 \\
\hline$\rho_{c, 0}:$ initial density of coal & $1250.0 \mathrm{~kg} / \mathrm{m}^{3}$ \\
\hline$\sigma:$ Stefan-Boltzmann constant & $5.6693 \times 10^{-8} \mathrm{~W} / \mathrm{m}^{2} \mathrm{~K}^{4}$ \\
\hline
\end{tabular}

TABLE 2

Source Terms

$\Gamma_{v}=-Z_{v} \rho_{\mathrm{m}} A_{d} \exp \left[-E_{\mathrm{d}} / \bar{R} T_{\mathrm{c}}\right]$

$\Gamma_{\mathrm{hc}}=\frac{-A_{\mathrm{hc}} \rho_{\mathrm{m}}\left[\rho_{\mathrm{m}} Y_{\mathrm{v}}\right]^{1 / 2} Y_{\mathrm{O}_{2}} \exp \left[-E_{\mathrm{hc}} / \bar{R} T_{\mathrm{g}}\right]}{\left[\mathrm{MW}_{\mathrm{v}}\right]^{1 / 2} \mathrm{MW}_{\mathrm{O}_{2}}}$

$\Gamma_{\mathrm{c}}=\frac{\text { NUM }}{\text { DENOM }}$

where

$$
\begin{aligned}
& \mathrm{NUM}=-\left(\frac{9 \rho_{\mathrm{g}, 0} D_{\mathrm{O}_{2,0}} P_{\mathrm{g}} Z_{0}}{8 \rho_{\mathrm{c}, 0} \mathrm{MW} \mathrm{W}_{\mathrm{O}_{2}} r_{\mathrm{c}, 0}}\right) \mathrm{MW}_{\mathrm{g}} Z_{\mathrm{fc}} Y_{\mathrm{O}_{2}} \frac{\rho_{\mathrm{m}}}{\rho_{\mathrm{g}}}\left(\frac{T_{\mathrm{g}}}{T_{0}}\right)^{0.75} \exp \left(-E_{1} / \bar{R} T_{\mathrm{c}}\right) \\
& \operatorname{DENOM}=Z^{1 / 3}\left(Z-Z_{\mathrm{fc}}+Z_{\mathrm{fc} 0}\right)^{2 / 3}\left[r_{\mathrm{c}, 0}\left(\frac{Z}{Z-Z_{\mathrm{fc}}+Z_{\mathrm{fc}}}\right)^{1 / 3} P_{\mathrm{g}} \exp \left(\frac{-E_{\mathrm{l}}}{\bar{R} T_{\mathrm{c}}}\right)\right. \\
& \left.+\rho_{\mathrm{g} .0} D_{0_{2} .0}\left(\frac{2 \pi \bar{R} T_{\mathrm{c}}}{\mathrm{MW}}\right)^{1 / 2}\left(\frac{T_{8}}{T_{0}}\right)^{0.75}\right] \\
& \Gamma_{\mathrm{CO}_{2}}=-\frac{\mathrm{MW}_{\mathrm{CO}_{2}}}{\mathrm{MW}_{\mathrm{c}}} \Gamma_{\mathrm{c}}-\frac{n \mathrm{MW}_{\mathrm{CO}}}{\mathrm{MW}} \Gamma_{\mathrm{hc}} \\
& \Gamma_{\mathrm{H}_{2} \mathrm{O}}=-\frac{m \mathrm{MW}_{\mathrm{H}_{2} \mathrm{O}}}{2 \mathrm{MW}_{\mathrm{v}}} \Gamma_{\mathrm{hc}}
\end{aligned}
$$


The gas is assumed transparent to radiation. For the dust concentrations considered here, this limit is most accurate at an equivalence ratio approaching 10 while cases treated here were for $\phi$ ranging from 3 to 8 .

\section{Boundary Conditions}

The general problem being considered here is the steady-state propagation of a flame into an initially quiescent mixture of coal dust and air. In the coordinate system used here the origin is attached to the moving flame and is maintained at some distance upstream from the central combustion region of the flame. The mixture of coal dust and air is taken to travel in the positive $x$-direction for $x=-\infty$, where the unreacted cold mixture exists, to $x=+\infty$, where the hot combustion products are assumed to have fully reacted. With this coordinate system the upstream boundary conditions refer to the cold, unreacted region at $x=-\infty$ and the downsteam boundary conditions refer to the hot region at $x$ $=+\infty$.

At $x=-\infty$ the dust and air mixture is assumed to be in thermal equilibrium at ambient temperature, given as $T_{\mathrm{c}}=T_{\mathrm{g}}=T_{0}$. The initial coal mass fraction $\left(Z_{0}\right)$ and the initial solid volatiles mass fraction $\left(Z_{v, 0}\right)$ are specified by the assumed equivalence ratio. The initial mass fraction of the fixed carbon component of the coal is thus determined by Eq. (12). The mass fractions $Y_{\mathrm{CO}_{2}}, Y_{\mathrm{H}_{2} \mathrm{O}}$, and $Y_{\mathrm{v}}$ are all zero at $x=$ $-\infty$, so the initial mass fraction of oxygen is determined by the assumed initial air composition and Eq. (11). The pressure $P_{\mathrm{g}}$ is held constant at one atmosphere, so the initial gas density, $\rho_{g, 0}$, is specified by Eq. (9). Similarly, the initial coal density, $\rho_{c, 0}$, can be determined using Eq. (10) once $Z_{\mathrm{v}, 0}$ has been specified. All first and second spatial derivatives are zero at $x$ $=-\infty$.

At $x=+\infty$, all of the oxygen in the air will be completely consumed by chemical reaction in these fuel rich flames. However, the mass fractions of $\mathrm{CO}_{2}$ and $\mathrm{H}_{2} \mathrm{O}$ at the hot boundary cannot be specified for fuel rich flames because the proportion of heterogeneous to homogene- ous combustion is not known a priori. However, by conservation of elements it is known that at steady state the total mass fractions of the elements must be the same as at the cold boundary. All of the first and second derivatives with respect to $x$ are equal to zero at $x=+\infty$. The particle and gas temperatures at $x=+\infty$ must be equal to each other, $T_{\mathrm{c}}=T_{\mathrm{g}}$, but the final adiabatic temperature cannot be determined a priori. The final adiabatic temperature must be a determined result of the solution ot the governing equations since the final temperature will be determined in part by the ratio of heterogeneous to homogeneous combustion.

\section{Transformations}

It has become common practice for combustion modelers to transform the governing equations through a type of stream function which is related to, but clearly different from, the stream function used in fluid mechanics [11-13]. The transformation function used here (in dimensional units) is defined by the relation

$\psi(x, t)=\int_{0}^{x} \rho_{\mathrm{m}}\left(x^{\prime}, t\right) d x^{\prime}$,

where $x^{\prime}$ is a dummy variable of integration. The physical interpretation of the function $\psi$ is that equal masses of mixture are contained between planes at which the $\psi$ values differ by equal amounts. The conservation of mass equation is identically satisfied in the stream coordinate system. Second, the convective terms in the governing equations are eliminated by using this transform. For example, Eq. (2) is transformed into the following:

$\rho_{\mathrm{m}} * \frac{\partial Z_{\mathrm{fc}}}{\partial t^{*}}+\rho_{\mathrm{m}} * \frac{\partial Z_{\mathrm{fc}}}{\partial \psi^{*}}=\mathrm{Da}_{1, \mathrm{c}} \Gamma_{\mathrm{c}}^{*}$

which contains no convective term.

A complete summary of the governing equations as they appear in the stream coordinate system is presented in Ref. [10].

The difficulties associated with computationally imposing the hot boundary conditions were reduced by employing a transformation 
which maps the location $x=+\infty$ into a finite value. The additional transformation used in this work is the hyperbolic tangent transform,

$t^{*}=t^{*} \quad \xi^{*}=\tanh \left[\left(\alpha^{*} \psi^{*}\right)^{\beta}\right]$

where $\alpha^{*}$ and $\beta$ are arbitrarily specified constants used to optimize the transformation. This transform is an extension of the hyperbolic tangent transform used by Galant $[14,15]$. This transform maps the semiinfinite domain of $(0$, $+\infty)$ into the finite domain of $(0,1)$. A plot of $\xi^{*}$ versus $\psi^{*}$ produces an $S$-shaped curve. Qualitatively, $\alpha^{*}$ is used to locate the inflection point of the S-like curve near a specific value of $\psi^{*}$, while $\beta$ determines the steepness by which the curve rises in the vicinity of the inflection point. By appropriately adjusting the values of $\alpha^{*}$ and $\beta$, it was possible to concentrate a large portion of the discrete points used in the numerical finite differencing scheme into the flames reaction zone where the gradients are the largest. Additionally, with this transformation the point $\xi^{*}=1$ corresponds to $\psi^{*}=+\infty$ (i.e., $x$ $=+\infty$ ), and the hot boundary conditions specified at $\xi^{*}=1$ are thus imposed at a great distance from the flame. Mathematically the hot boundary conditions should be imposed at infinity, but numerical considerations result in the conditions actually being imposed at some large, but finite, distance from the flame.

Using appropriate identities for the hyperbolic functions, it can be shown that the derivative of $\xi^{*}$ with respect to $\psi^{*}$ can be expressed as

$\frac{\partial \xi^{*}}{\partial \psi^{*}}=\alpha^{*} \beta\left(1-\xi^{* 2}\right)\left[\frac{1}{2} \ln \left(\frac{1+\xi^{*}}{1-\xi^{*}}\right)\right]^{(\beta-1) / \beta}$,

which is a purely geometric relation in $\xi^{*}$ once $\alpha^{*}$ and $\beta$ are specified. This function asymptotes to 0 as $\xi^{*} \rightarrow 0$ and as $\xi^{*} \rightarrow 1$, and reaches a maximum at $\xi^{*}$ somewhat larger than $1 / 2$. With Eq. (17), it is then a straightforward matter to use the chain rule to convert the equations from the $\left(\psi^{*}, t^{*}\right)$ domain to the $\left(\xi^{*}, t^{*}\right)$ domain. The resulting equations were solved by the technique discussed below.

\section{SOLUTION TECHNIQUE}

The method of lines (MOL) is a straightforward, reliable, and relatively robust technique to approximate the solution of initial value problems for systems of linear and nonlinear partial differential equations (PDEs) [16]. The method is capable of solving a wide variety of different types of PDEs, and it has been successfully applied to such diverse equations as the nonlinear wave equation and nonlinear elliptic boundary value problems as well as the chemical reaction diffusion equations of interest here. $\mathrm{A}$ disadvantage with the MOL is that it requires that an initial set of solution profiles at some specified time (normally zero) be guessed or determined. The guessed profiles do not have to be very close to the correct final profiles, but they do have to satisfy numerically the boundary conditions and the conservation of mass (species) equations, everywhere.

A PDE may be solved with the MOL in the following manner. The solution of the equation is first approximated by a set of values at discrete points throughout the domain of interest. If, for example, the PDE is a function of space and time, then typically the solution is approximated at some time by values at specific discrete points throughout the space domain. If a solution of the equation is not known a priori, then the initial approximating solution is a guessed input. The derivatives with respect to the discretized variable are then approximated by any of several numerical methods. In this case, the spatial derivatives have been approximated by finite difference schemes or by fitting a curve through the discrete points and differentiating the fitted curve. At this point the PDE has been reduced to a system of initial valued ODEs, one ODE for each discrete point in the space domain. Powerful integration packages which are available are then used to integrate the system of ODEs with respect to the remaining independent variable-time in this problem. As integration proceeds, the derivatives with respect to the discretized variable must be periodically updated since the values at the discrete points will change at individual rates. If more 
than one governing equation is involved, then the interaction between the equations must also be updated periodically. The integration is thus normally performed in uniform steps. These global steps may or may not have any correlation with the internal integration step sizes chosen by the numerical integration package used to integrate the systems of ODEs. When a system of PDEs is solved with the MOL, the procedure is identical for each equation individually. Details may be found in Ref. [10].

The integration package used to integrate the systems of ODEs produced by the MOL was the August 1981 version of LSODE. This is a general ODE solver from Lawrence Livermore National Laboratory authored by Hindmarsh [17]. The LSODE package is based on the original GEAR and GEARB packages, but is more efficient than the other packages. A single method flag may be used to control the type of integration used for a given set of equations. Nonstiff equations are integrated by an Adams method, while stiff equations may be integrated by implicit backward differencing techniques requiring full or banded Jacobians which may be supplied or internally generated. This package allows the user considerable control over the integration performed by the package.

\section{CALCULATEd RESUlts}

\section{Convergence Properties}

Since the method of lines is a transient solution technique which integrates until a steady-state solution is obtained, convergence criteria were required to determine when a solution was acceptably close to the "true" steady-state value. Several general criteria were used to decide when a set of profiles for the dependent variables had converged sufficiently and no further integration was required. The two main criteria used here were that all of the velocities computed over the various species profiles all converged to approximately the same value, and that all the solution profiles ceased to change with time. Additionally, the elemental mass fractions computed at each location throughout the flame were required to be within $0.1 \%$ of the elemental mass fractions computed for the incoming unreacted cold mixture.

One can show [10] that the flame speed based on the consumption of the mass fraction of the solid coal, $Z$, is derived from the integration performed as follows:

$$
\begin{aligned}
u_{0}(Z) & =\left[\frac{D_{\mathrm{g}, 0}}{Z_{\infty}-Z_{0}}\right. \\
\times \int_{\xi^{*}=0}^{\xi^{*}=1} & \left.\frac{\left(A_{\mathrm{d}} \Gamma_{\mathrm{v}}{ }^{*}+A_{\mathrm{c}} \Gamma_{\mathrm{c}}{ }^{*}\right) d \xi^{*}}{\rho_{\mathrm{m}}{ }^{*}\left(\partial \xi^{*} / \partial \xi^{*}\right)}\right]^{1 / 2} .
\end{aligned}
$$

Similar relations may be derived for computing the velocity based upon the profiles for each of the species.

The individual velocities computed for the various species with the guessed starting profiles typically were not the same. With the starting profiles used here, the difference between the highest and lowest individual velocities was usually at least $2 \mathrm{~m} / \mathrm{s}$, although differences as large as $10 \mathrm{~m} / \mathrm{s}$ were not unusual. The average of the velocities was also normally at least an order of magnitude larger than the velocity computed at steady state. The high initial velocities were expected since the initial profiles were guessed so that the mass fraction of oxygen was everywhere positive and its value at the hot boundary was approximately $1 \%$ of the cold boundary value. Computationally, this amounted to a large amount of oxygen remaining at the hot boundary. The large amount of oxygen throughout the domain resulted in large initial reaction rates for both the heterogeneous and homogeneous reaction rates $\left(\Gamma_{c}\right.$ and $\Gamma_{h c}$, respectively). Since the velocity calculations involve integrals over the reaction rates, the initial velocities were high. The surplus oxygen within the system was quickly consumed, however, and the computed velocities normally converged to within about $50 \%$ of the final values within the first 100 global time steps.

For all of the solutions presented in the study the individually computed velocities were all within $1.5 \%$ of the mean value. More specifically, the individual velocities always con- 
verged to within $\pm 0.5 \mathrm{~cm} / \mathrm{s}$ of the average velocity. This degree of convergence compares very favorably with those observed by other authors where computed flame speeds are generally within $5 \%$. For example, the flame velocities of Smoot and Horton [13] converged to within approximately $10 \%$. In the study, if the integration was continued far beyond the point where the velocities had satisfactorily converged, the average velocity was found to oscillate slowly about the values reported. The velocities slowly varied by approximately \pm 0.2 $\mathrm{cm} / \mathrm{s}$.

Physically, the mass fractions for the individual elements $(\mathrm{C}, \mathrm{H}, \mathrm{O}, \mathrm{N})$ in a mixture cannot change regardless of the chemical reactions which occur in the mixture. Although the overall conservation of mass relation [Eq. (11)] may be satisfied throughout the flame by the initial guessed profiles, the elemental mass fractions will not be constant throughout the flame until the steady-state solution profiles are obtained. Thus, an additional criterion for convergence to the final profiles is that the elemental mass fractions are acceptably constant throughout the flame. The selection of initial guessed profiles was greatly improved by using the conservation of elemental mass fractions relation to determine the largest mass fractions (in absolute value) from the guessed profiles for the minor species. Specifically, only the species profiles for $\mathrm{CO}_{2}, \mathrm{H}_{2} \mathrm{O}$, and the gaseous volatiles $\left(\mathrm{C}_{3} \mathrm{H}_{8}\right)$ were guessed. Conservation of the elemental mass fraction of hydrogen was then used to determine the profile for $Z$ (composed of $\mathrm{C}$ and $\mathrm{C}_{3} \mathrm{H}_{8}$ ). With $Z$ determined, conservation of the elemental mass fraction of carbon could be used to determine the initial profile for $Z_{\mathrm{fc}}$. The elemental mass fraction of nitrogen was identically constant everywhere and computed from the cold boundary conditions.

The accuracy of the computed results is somewhat dependent on the number of grid points used in spatial discretization. In general, the larger the number of points used, the better the accuracy. For all of the final profiles presented here the space domain (the $\xi^{*}$ coordinate) contained 201 equally spaced points.
Computation times varied greatly with the accuracy of the assumed initial profiles. The required computer time was reduced as experience was gained and better initial guesses could be made. The first solutions could also be used in large part as initial guesses for obtaining solutions for cases with only one parameter changed by a relatively small amount. In terms of actual calculation times, later solutions could be obtained within approximately $1000 \mathrm{~s}$ of CPU time on a CYBER 175.

The ability of the method of lines solution technique to converge to a steady-state solution despite large differences between the guessed initial profiles and the correct steady-state profiles is illustrated in Fig. 1. This figure shows the relaxation of the gas temperature profile from an initial guess to the final steady-state solution for a mixture with $50 \mu \mathrm{m}$ particles and a coal concentration three times the stoichiometric value. The first "initial" profile is labeled A. The cold boundary value (at $\xi^{*}=0$ ) was set equal to $T_{0}$ (i.e., $298 \mathrm{~K}$ ), and the derivative near the hot boundary was forced to be zero. A hot boundary value of $2000 \mathrm{~K}$ was selected because it was slightly higher than the stoichiometric adiabatic flame temperature (1975K). The temperature profile thus resulted in sufficient energy being released in the flame to provide "ignition" and maintain the chemical reactions. The small rounded peak in the guessed gas temperature profile was based on the temperature profiles predicted by Krazinski et al. [2] and Smoot et al. [1].

Since no solutions existed for any set of input conditions (particle size, equivalence ratio, heats of reaction, etc.) at the time that profile $\mathrm{A}$ in Fig. 1 was assumed, little was known about the convergence characteristics of the solution technique. Therefore little operator input could be used to accelerate the convergence rate manually. When profile $A$ was integrated to profile $B$, the temperature rise was observed to become steeper and the overall profile appeared to be tending toward a step function. In real $(x)$ space the flame was observed to become thinner. Therefore new values of $\alpha^{*}$ and $\beta$ were used in the hyperbolic tangent transform to concen- 


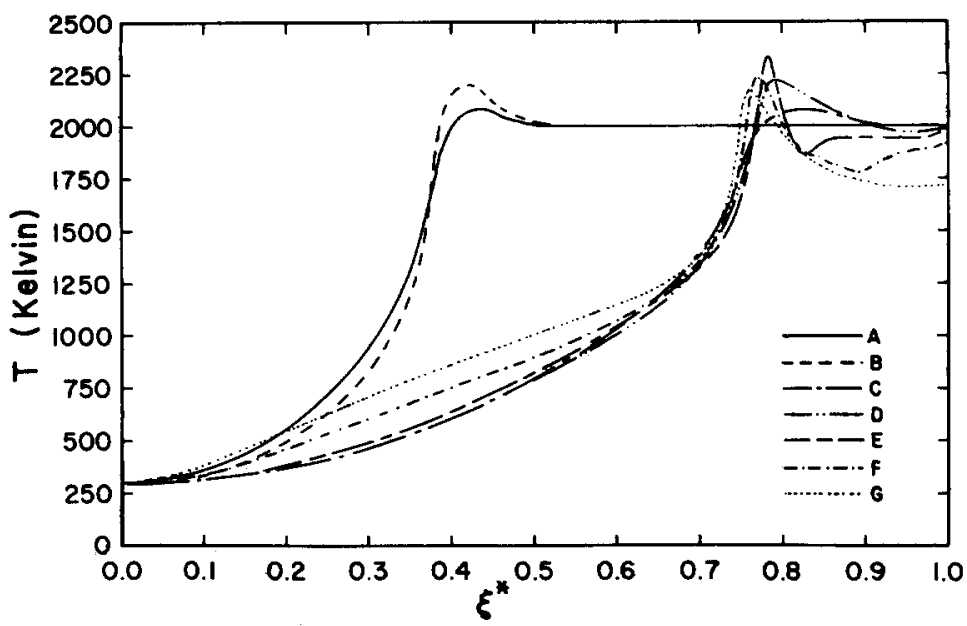

Fig. 1. Example of temperature profile convergence from an initial guessed profile.

trate more points into the relatively thin reaction zone of profile $A$. The new profile which resulted is that of profile $C$ in Fig. 1. Although profiles $A$ and $C$ are very different from each other in the $\xi^{*}$ domain, the differences are strictly due to the different values of $\alpha$ and $\beta$ associated with each profile. The real ( $x$-space) profiles were identical. No further operator input was made as profile $\mathrm{C}$ was integrated in time. The temperature profile changed from $\mathrm{C}$ through $D$ to $E$ while large changes were occurring in the hot region over relatively small times. In the early integration time the fuel rich adiabatic flame temperature decreased well below the guessed value which was based on stoichiometric calculations. With additional integration for large times the precombustion zone temperature increased and the postcombustion zone profile smoothed out to the final computed adiabatic flame temperature of about $1720 \mathrm{~K}$, as shown in profiles E, F, and G. The difference between the initial guessed profile $(C)$ and the final profile $(G)$ is readily apparent. The peak temperture is over $100 \mathrm{~K}$ higher than in profile $C$, while the adiabatic flame temperature is about $300 \mathrm{~K}$ cooler than guessed. The peak in the temperature profile is also much sharper than initially assumed.

Figure 2 shows the relaxed (steady-state) profile in real $x$-space of the gas and particle temperatures for an equivalence ratio of 5 for particles having an initial diameter of $35 \mu \mathrm{m}$. The predicted steady-state flame velocity is $\mathbf{4 0 . 2}$ $\mathrm{cm} / \mathrm{s}$. Figure 3 shows the mass fractions which correspond to the temperature profiles given in Fig. 2. Detailed results are presented in Ref. [10], showing the effect of the transformation constants, grid spacing, and general input parameters.

\section{Equivalence Ratio Effects}

The effect that varying the equivalence ratio had on the computed burning velocity and the predicted temperatures was of prime interest in this work. The equivalence ratio, $\phi$, is defined as

$\phi=\frac{\text { actual[(mass of fuel) } /(\text { mass of air)] }}{\text { stoichiometric[(mass of fuel)/(mass of air)] }}$

For the coal assumed here, i.e., $\mathrm{CH}_{0.8} \rightarrow 0.7 \mathrm{C}$ $+0.1 \mathrm{C}_{3} \mathrm{H}_{8}$, the stoichiometric concentration of coal was $0.0917 \mathrm{~kg} / \mathrm{m}^{3}$.

The variation of computed burning velocity with $\phi$ for a constant initial particle diameter of $50 \mu \mathrm{m}$ is shown in Fig. 4. The velocity is seen to reach a very flat peak of $37 \mathrm{~cm} / \mathrm{s}$ near $\phi=4$, then drop to $9 \mathrm{~cm} / \mathrm{s}$ as the equivalence ratio is increased to 8. Data were not obtained near enough to $\phi=1$ to make a reliable prediction of the stoichiometric burning velocity. This makes it somewhat difficult to compare directly the 


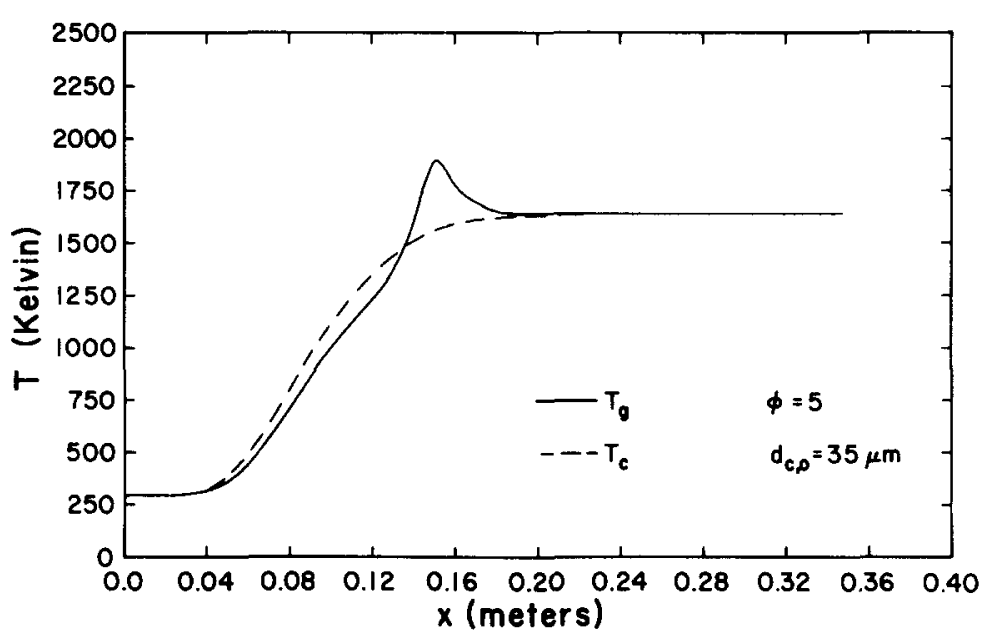

Fig. 2. Example of temperature profiles in real space: $\phi=5 ; d_{c, 0}=35 \mu \mathrm{m} ; u_{0}=40.2$ $\mathrm{cm} / \mathrm{s}$.

works of Krazinski et al. [2] and Bhaduri and Bandyopadhyay [5] with these results since those studies presented data only for $\phi \leq 1$. For coal particles of $50 \mu \mathrm{m}$, however, Bhaduri and Bandyopadhyay computed a velocity of 35.5 $\mathrm{cm} / \mathrm{s}$ at $\phi=0.83$ for an anthracite coal. Krazinski et al. predicted a stoichiometric flame velocity of $90 \mathrm{~cm} / \mathrm{s}$ for $50 \mu \mathrm{m}$ diameter coal particles containing $36 \%$ volatiles. Smoot et al. [1] predicted a peak velocity of $17.5 \mathrm{~cm} / \mathrm{s}$ for 33 $\mu \mathrm{m}$ coal (50\% volatiles) near $\phi=4$, and velocities of $16 \mathrm{~cm} / \mathrm{s}$ near $\phi=3$ and $17 \mathrm{~cm} / \mathrm{s}$ near $\phi=7$. Smoot et al. did not report data for $50 \mu \mathrm{m}$ particles, but they predicted higher burning velocities for $10 \mu \mathrm{m}$ coal, indicating that their work would probably predict even smaller velocities for $50 \mu \mathrm{m}$ particles than the values given here for $33 \mu \mathrm{m}$ particles. Although the velocities predicted by Smoot et al. are generally about half of those computed here, the variation of velocity with equivalence ratio predicted by Smoot et al. compares well with this study.

The variation in temperature with equivalence

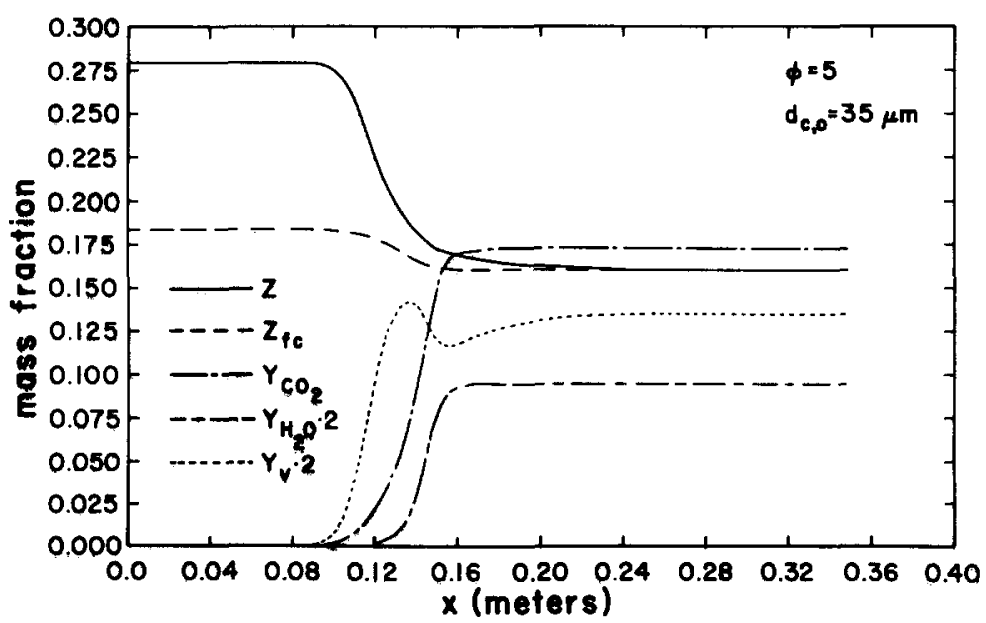

Fig. 3. Example of mass fraction profiles in real space: $\phi=5 ; d_{c .0}=35 \mu \mathrm{m} ; u_{0}=40.2$ $\mathrm{cm} / \mathrm{s}$. 


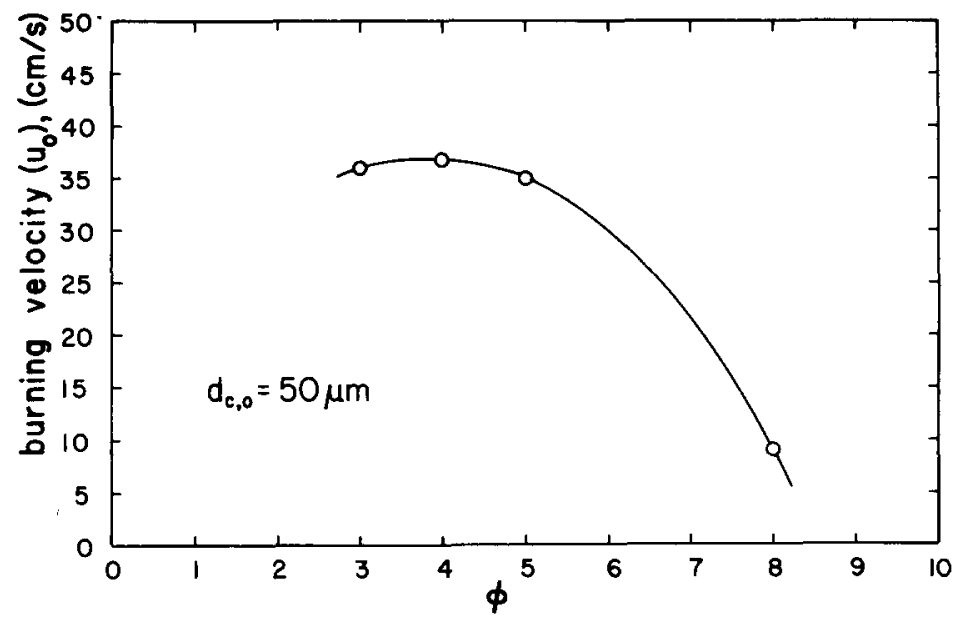

Fig. 4. Computed burning velocity versus equivalence ratio at constant particle size $\left(d_{\mathrm{c}, 0}\right.$ $=50 \mu \mathrm{m})$.

ratio is readily evident from Fig. 5, which shows the gas temperature profile for various values of $\phi$ and a constant particle diameter of $50 \mu \mathrm{m}$. Both the peak temperature and the adiabatic flame temperature decrease monotonically with increasing $\phi$. The peak gas temperature decreases from about $2200 \mathrm{~K}$ at $\phi=3$ to $1400 \mathrm{~K}$ at $\phi=8$, while the corresponding adiabatic temperatures decrease less dramatically from 1700 to $1400 \mathrm{~K}$. The decrease in the temperatures is almost exclusively due to the energy absorbed in heating up the additional coal which is unable to partici- pate in the chemical reactions as the equivalence ratio is increased. The temperatures also change somewhat due to a small change in the relative amount of coal consumed by homogeneous reaction to that consumed by heterogeneous reaction. In general, though, the ratio of the amount of heterogeneous combustion to the amount of homogeneous combustion is relatively constant over the equivalence ratios presented here.

\section{Particle Size Effects}

The last result of this study is the predicted

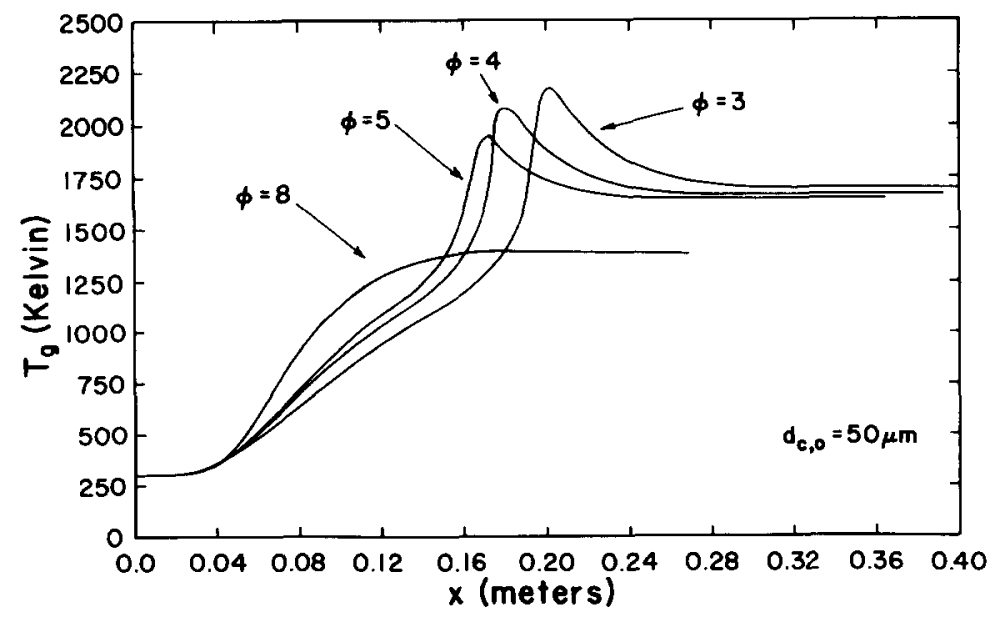

Fig. 5. Gas temperature profiles for various equivalence ratios at constant particle size $\left(d_{c, 0}=50 \mu \mathrm{m}\right)$. 


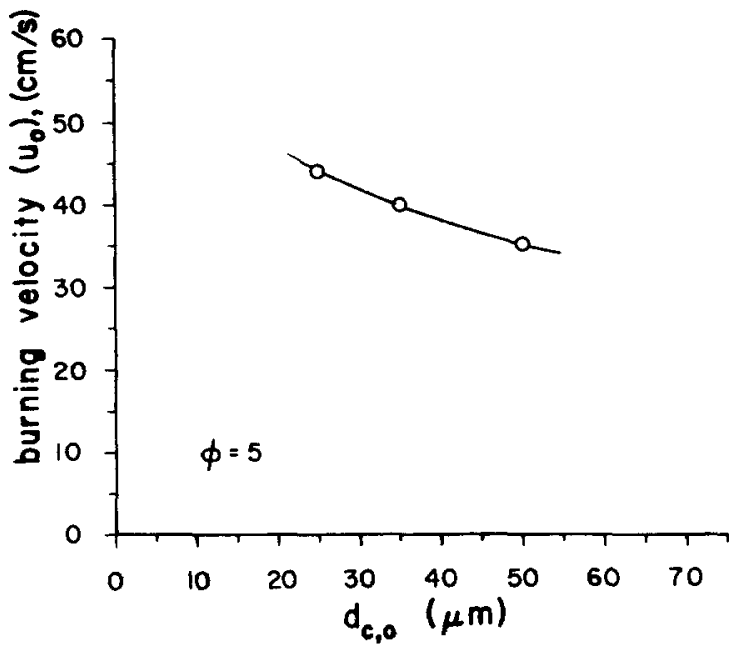

Fig. 6. Computed burning velocity versus particle size at constant equivalence ratio $(\phi=5)$.

steady-state flame speed as a function of coal particle size. This is shown in Fig. 6. The predicted flame thickness decreased and the gas and particle temperatures converged with decreasing particle diameter for the same reasons that were observed for increasing $\phi$. As the particle size decreased at constant $\phi$, the total coal surface area over which convective heat transfer could occur was increased. The increased convective heat transfer allowed the hot particles to "pull up" the gas temperature more quickly. This, in turn, created thinner flames and higher burning velocities. In addition, the flames also became thinner with decreasing particle size due to the corresponding increase in the radiation extinction coefficient. At a constant equivalence ratio the extinction coefficient is inversely proportional to the particle diameter. Therefore, as the diameter decreases the radiant energy cannot penetrate as far into the mixture, and the coal cannot be heated by radiation farther ahead of the flame. This tends to decrease the burning velocity. The surface area per unit mass of the particles increases as diameter decreases, however, so the radiative heat transfer is able to heat the particles more quickly. The net effect is a gentle increase in burning velocity with decreasing particle size.

\section{CONCLUDING REMARKS}

This paper presents solutions to a comprehensive two-phase flow combustion model for rich mixtures of coal dust in air. Properties of the coal dust were typical for pulverized bituminous coals studied experimentally [3].

The model used here contains a simplified single step reaction for both heterogeneous combustion of the char and homogeneous combustion of the evolved volatile matter. A single step scheme was used to model the devolatilization of the coal particles. The optically thick approximation for radiative heat transfer was included in the model.

The agreement between the predictions of the analytical model developed here and the experimental results reported in Ref. [3] is surprisingly good. The experimentally observed peak burning velocity of $33 \mathrm{~cm} / \mathrm{s}$ compares very well with the predicted value of $37 \mathrm{~cm} / \mathrm{s}$, although the peaks occurred at somewhat different values of $\phi$. Thus, it is very important to stress here that the good agreement between the analytical and experimental values is highly fortuitous, but not contrived. The important rate constants used in the model, reported in Ref. [2], were not adjusted to give desired predictions. They were chosen from experimental values obtained by others working with coal similar to that used in this experimental effort [2]. Many of the values are identical to those used by both Smoot et al. [1] and Krazinski et al. [2] in their modeling efforts.

The burning velocities predicted by the analytical model developed here not only compared well with the magnitude of the experimental values; they also compared well with the trends in the experimental data. Figure 5 from Ref. [3] indicates that the experimental buming velocities have a very broad peak of $33 \mathrm{~cm} / \mathrm{s}$ at approximately $0.7 \mathrm{~kg} / \mathrm{m}^{3}$. The velocity fell to about $20 \mathrm{~cm} / \mathrm{s}$ at the lean limit of $0.43 \mathrm{~kg} / \mathrm{m}^{3}$ and at the extremely rich concentration of about 1.2 $\mathrm{kg} / \mathrm{m}^{3}$. The stoichiometric concentration of Pittsburgh Seam bituminous coal is approximately $0.11 \mathrm{~kg} / \mathrm{m}^{3}$. Thus, in terms of equivalence ratio, the experimentally measured lean 
limit is approximately $\phi=3.9$, the peak velocity was found to be near $\phi=6.4$, and velocities near $20 \mathrm{~cm} / \mathrm{s}$ occurred at concentrations near $\phi=11$. The predicted flame velocities followed a similar trend. The velocity was relatively constant at about $36 \mathrm{~cm} / \mathrm{s}$ for equivalence ratios near 4 , but decreased to $9 \mathrm{~cm} / \mathrm{s}$ for $\phi=8$.

The temperatures which were measured experimentally [3] with thermocouples are not highly reliable, but peak temperatures near $1200 \mathrm{~K}$ were regularly measured for concentrations near $0.6 \mathrm{~kg} / \mathrm{m}^{3}$. As the concentration of coal increased to $1.2 \mathrm{~kg} / \mathrm{m}^{3}$, the measured flame temperatures became both lower and more unreliable. Peak temperatures at the very high concentrations, however, did not exceed $1000 \mathrm{~K}$. As expected, these temperatures are considerably lower than the adiabatic flame temperatures predicted in this model, particularly since $\mathrm{CO}$ was not included in the model. The lowest computed adiabatic flame temperature (for $\phi=$ 8) is $1400 \mathrm{~K}$, while the stoichiometric adiabatic flame temperature for the coal in the model is $1975 \mathrm{~K}$. Although the experimental temperatures are roughly $500 \mathrm{~K}$ lower than the analytical predictions here, they are very comparable to temperatures measured with the thermocouples by others using steady-state burners $[15,16]$.

Finally, as indicated above, we are well aware that the simple chemistry used in this model does not adequately include all the major species that exist in real coal dust flames. Certainly the formation of $\mathrm{CO}$ and $\mathrm{H}_{2}$ becomes more significant as the mixtures become more fuel rich. We are planning to revise this model in the near future, to include results which also model $\mathrm{CO}$ and $\mathrm{H}_{2}$, as well as four elementary heterogeneous reactions and three homogeneous reactions. But we expect that the increased complexity of the kinetics will greatly increase the computational costs of obtaining steady-state solutions.

\section{NOMENCLATURE}

$A_{\mathrm{d}}, A_{\text {he }} \quad$ preexponential factors (units depend on rate expressions)

\begin{tabular}{|c|c|}
\hline$C_{\mathrm{p}}$ & specific heat $(\mathrm{J} / \mathrm{kg} \mathrm{K})$ \\
\hline$d$ & diameter $(\mathrm{m})$ \\
\hline$D$ & diffusion coefficients $\left(\mathrm{m}^{2} / \mathrm{s}\right)$ \\
\hline & Damkohler number \\
\hline$E_{1}, E_{\mathrm{d}}, E_{\mathrm{hc}}$ & $\begin{array}{l}\text { activation energies for absorp- } \\
\text { tion, devolatilization, and hydro- } \\
\text { carbon reaction, respectively (J/ } \\
\mathrm{kmol})\end{array}$ \\
\hline$F_{\mathrm{gc}}$ & $\begin{array}{l}\text { heat transfer lag coefficient (W/ } \\
\left.m^{3} \mathrm{~K}\right)\end{array}$ \\
\hline$h_{\mathrm{cg}}{ }^{0}$ & $\begin{array}{l}\text { latent heat of devolatilization }(\mathrm{J} / \\
\mathrm{kg} \text { ) }\end{array}$ \\
\hline$h_{\text {coal }}{ }^{0}$ & $\begin{array}{l}\text { energy released in the solid phase } \\
(\mathrm{J} / \mathrm{kg})\end{array}$ \\
\hline$h_{\mathrm{hc}}{ }^{0}$ & heat of reaction of volatiles $(\mathrm{J} / \mathrm{kg})$ \\
\hline$h_{\text {het }}{ }^{0}$ & $\begin{array}{l}\text { heterogeneous heat of reaction }(\mathrm{J} / \\
\mathrm{kg})\end{array}$ \\
\hline$L_{\mathrm{c}}$ & characteristic length $\left(=D_{g, 0} / u_{0}\right)$ \\
\hline$m$ & $\begin{array}{l}\text { hydrogen subscript in chemical } \\
\text { formula for volatiles }\end{array}$ \\
\hline MW & molecular weight $(\mathrm{kg} / \mathrm{kmol})$ \\
\hline$n$ & $\begin{array}{l}\text { particle number density }\left(\mathrm{m}^{-3}\right) \text { or } \\
\text { carbon subscript in chemical for- } \\
\text { mula for volatiles }\end{array}$ \\
\hline$\underline{P}$ & pressure $(\mathrm{Pa})$ \\
\hline $\bar{R}$ & gas constant $(\mathrm{J} / \mathrm{kmol} \mathrm{K})$ \\
\hline$t$ & time (s) \\
\hline $\begin{array}{l}t_{\mathrm{r}} \\
T\end{array}$ & $\begin{array}{l}\text { reference time }\left(=D_{\mathrm{g}, 0} / u_{0}^{2}\right) \\
\text { temperature }(\mathrm{K})\end{array}$ \\
\hline$T_{\mathrm{r}}$ & $\begin{array}{l}\text { reference temperature (a stoi- } \\
\text { chiometric adiabatic flame tem- } \\
\text { perature) }\end{array}$ \\
\hline$u$ & velocity $(\mathrm{m} / \mathrm{s})$ \\
\hline$v$ & volatiles fraction in the coal \\
\hline$x$ & distance $(\mathrm{m})$ \\
\hline$X$ & mole fraction \\
\hline$Y$ & $\begin{array}{l}\text { mass fraction (mass of gaseous } \\
\text { species } i \text { per mass of mixture) }\end{array}$ \\
\hline$Z, Z_{\mathrm{fc}}, Z_{\mathrm{v}}$ & $\begin{array}{l}\text { mass of coal, fixed carbon, and } \\
\text { volatiles which have not yet gasi- } \\
\text { fied, respectively, per mass of } \\
\text { mixture }\end{array}$ \\
\hline
\end{tabular}

\section{Greek Symbols}

$\alpha$

$2 \pi r_{\mathrm{c}} / \lambda$ or selected constant in transform to hyperbolic coordinate 
$\beta \quad$ selected constant in transform to hyperbolic coordinate

$\epsilon \quad$ volume fraction of coal

$\Gamma \quad$ source term $\left(\mathrm{kg} / \mathrm{m}^{3} \mathrm{~s}\right)$

$\kappa \quad$ extinction coefficient $\left(\mathrm{m}^{-1}\right)$

$\lambda_{g}$ thermal conductivity of gas $(\mathrm{W} / \mathrm{m}$ $\mathrm{K})$

$\rho$ density $\left(\mathrm{kg} / \mathrm{m}^{3}\right)$

$\sigma$ Stefan-Boltzmann constant (W/ $\mathrm{m}^{2} \mathrm{~K}^{4}$ )

$\xi \quad$ hyperbolic coordinate

$\psi \quad$ stream coordinate

\section{Subscripts}

$\begin{array}{ll}\mathrm{c} & \text { coal } \\ \mathrm{CO}_{2} & \text { carbon dioxide } \\ \mathrm{g} & \text { gas } \\ \mathrm{hc} & \text { hydrocarbon } \\ \mathrm{H}_{2} \mathrm{O} & \text { water } \\ \mathrm{m} & \text { mixture } \\ \mathrm{N}_{2} & \text { nitrogen } \\ 0 & \text { conditions at cold end } \\ \mathrm{O}_{2} & \text { oxygen } \\ \mathrm{v} & \text { volatiles } \\ \infty & \text { conditions at the hot boundary }\end{array}$

\section{Superscripts}

*

indicates a nondimensional quantity

indicates a dummy variable of integration

This work was supported, in part, by the National Science Foundation under Contract NSF 77-26973 and the Center for Research on Sulfur in Coal (ST-ILENR-2-CRB). The authors acknowledge the work of Mr. N. Y. Wang, who assisted in a portion of the computer calculations presented here. This work was carried out at the University of Illinois at Urbana-Champaign.

\section{REFERENCES}

1. Smoot, L. D., and Horton, M. D., Prog. Energy Combust. Sci. 3:235-258 (1977).

2. Krazinski, J. L., Buckius, R. O., and Krier, H., Prog. Energy Combust. Sci. 5:31-77 (1979).

3. Slezak, S. E., Fitch, D. J., Krier, H., and Buckius, R. O., Combust. Flame 54:103-119 (1983).

4. Essenhigh, R. H., and Csaba, J., Ninth Symposium (International) on Combustion, Academic Press, New York, 1963, pp. 111-117.

5. Bhaduri, D., and Bandyopadhyay, S., Combust. Flame 17:15-19 (1971).

6. Ozerova, G. E., and Stepanov, A. M., Combustion, Explosion, and Shock Waves 9:543-549 (1973).

7. Soo, S. L., Fluid Dynamics of Multiphase Systems, Blaisdell, Waltham, MA, 1967.

8. Stambuleanu, A., Flame Combustion Processes in Industry, Abacus Press, Tunbridge Wells, Kent, 1976.

9. Edelman, R. B., and Harsha, P. T., Prog. Energy Combust. Sci. 4:1-62 (1978).

10. Slezak, S. E., Ph.D. Thesis, Department of Mechanical and Industrial Engineering, University of Illinois at Urbana-Champaign, IL, 1984.

11. Spalding, D. B., Phil. Trans. Roy. Soc. London A249:1-25 (1956).

12. Margolis, S. B., J. Comp. Phys. 27:410-427 (1978).

13. Smoot, L. D., and Horton, M. D., BYU Final Report USBM Grant G0177034, 1978, p. 315. (Available from NTIS.)

14. Galant, S., Ph.D. Thesis, Mech. Engr. Dept., MIT, 1976.

15. Galant, S., Eighteenth Symposium (International) on Combustion, The Combustion Institute, Pittsburgh, 1981, pp. 1451-1459.

16. Hyman, J. M., Courant Institute of Mathematical Sciences, C00-3077-139, October, 1976.

17. Hindmarsh, A. C., Lawrence Livermore Laboratories Report UCID 30130, 1976.

18. Mackowski, D. W., Altenkirch, R. A., Peck, R. E., and Tong, T. W., Paper No. 22, presented at the Western States Meeting of The Combustion InstituteSpring Meeting, 1982, Salt Lake City, Utah.

Received 18 May 1984; revised 28 September 1984 